ARTICLE OPEN

\title{
Evidence of major secondary organic aerosol contribution to lensing effect black carbon absorption enhancement
}

\author{
Yunjiang Zhang ${ }^{1,2}$, Olivier Favez ${ }^{1}$, Francesco Canonaco ${ }^{3}$, Dantong Liu (iD ${ }^{4}$, Griša Močnik ${ }^{5}$, Tanguy Amodeo ${ }^{1}$, Jean Sciare ${ }^{6}$, \\ André S. H. Prévôt ${ }^{3}$, Valérie Gros ${ }^{2}$ and Alexandre Albinet ${ }^{1}$
}

Atmospheric black carbon (BC) has a strong positive, but still controversial, effect on global warming. In particular, BC absorption enhancement $\left(E_{\mathrm{abs}}\right)$ due to internal mixing with other chemical species-so-called lensing effect-is poorly assessed. This bottleneck partly relies on the lack of long-term in situ measurements of both the optical and chemical properties of BC-containing particles. Here, we present experimental and computational results showing a significant $E_{\text {abs }}$ increase with the aerosol photochemical aging. This was associated with the production of highly oxidized secondary organic aerosols (SOA), especially at summertime. The 3-year-long continuous aerosol chemical and optical measurements used for the present study was obtained in the Paris region, France, which might be representative of near-future air quality within developing countries. These findings suggest that SOA could represent one of the most critical chemical species to be considered within climate models.

npj Climate and Atmospheric Science (2018)1:47; https://doi.org/10.1038/s41612-018-0056-2

\section{INTRODUCTION}

Black carbon $(\mathrm{BC})$ is wide-spread in the Earth's atmosphere and has a significant impact on global warming by absorbing solar radiation. ${ }^{1}$ Beyond the direct radiative forcing of pure $\mathrm{BC}$ particles, its climate impact is even increased in case of internal mixing with scattering material that focus more photons onto the BC core. ${ }^{2-4}$ This so-called 'lensing effect' leads to BC absorption enhancement $\left(E_{\text {abs }}\right)$, which must be considered by climate models. ${ }^{1,2}$ However, the scientific community is currently facing conflicting evidences from various field measurements, laboratory studies and/or modeling results about the actual magnitude of $E_{\text {abs }}$ values in the atmosphere. ${ }^{1,5-9}$ Furthermore, it is not clear yet which type of coating material has the most significant effect on $E_{\mathrm{abs}}$, leading to large uncertainties within calculations of the near-term BC global warming effect. ${ }^{10} \mathrm{~A}$ recent dispute between Jacobson ${ }^{11}$ and Cappa et al. ${ }^{12}$ illustrated the need for long-term field measurements to resolve these issues. Such datasets should include the observation of highly processed aerosols to be fully representative of $\mathrm{BC}$ radiative forcing at global scale. ${ }^{13}$

Recent sophisticated instrumentation can be used for direct measurements of the BC coating chemical composition. For instance, single particle aerosol mass spectrometers, possibly equipped with a thermodenuder to remove semi-volatile material internally mixed with $\mathrm{BC}$, provide information on the size-resolved chemical composition and internal mixing state of carbonaceous particles. $^{6-8}$ Nevertheless, such techniques are hardly suited for continuous measurements over multi-year periods. In the present study, we could instead make use of simple but robust monitors (Methods) to get clues about the source-dependent chemical composition, as well as photochemical age of aerosol fractions likely influencing the lensing effect. Measurements were performed from March 2014 to March 2017 at a suburban background site (SIRTA), located $25 \mathrm{~km}$ Southwest of Paris city center, France. This site is known to be influenced by both fresh and aged aerosols. Regarding primary aerosols on the one hand, it has notably been demonstrated as impacted by road transport emissions all around the year and residential wood burning during the winter season, both of them mainly originating from the Paris area. $^{14-16}$ Considering the effects of mitigation policies and the decline of industrial activities in North-Western Europe in the last decades, this region of the world may be considered as illustrative of probable future air quality conditions in developing countries currently moving towards similar way of life and environmental regulations.

\section{RESULTS}

Besides BC and lensing effects, light absorption by carbonaceous aerosols can also be related to the presence of absorbing organic aerosols, known as brown carbon $(\mathrm{BrC})$, either internally or externally mixed with $\mathrm{BC}$ particles. ${ }^{17,18}$ However, while $\mathrm{BrC}$ influence may be significant at ultraviolet wavelengths, it is negligible at (near-)infrared regions. ${ }^{18}$ In the present study, $E_{\mathrm{abs}}$ timeseries were obtained at 7 wavelengths ranging from nearultraviolet to near-infrared (namely at 370, 470, 520, 590, 660, 880, and $950 \mathrm{~nm}$ ). For illustration purpose, Fig. 1 presents daily variation of $\mathrm{BC}$ absorption enhancement at $370 \mathrm{~nm}\left(E_{\mathrm{abs}-370}\right)$ and $880 \mathrm{~nm}\left(E_{\text {abs-880 }}\right)$ over the whole studied period. Both timeseries displayed significant fluctuations, with 95th percentile values up to around 2 for $E_{\mathrm{abs}-880}$ and 3 for $E_{\mathrm{abs}-370}$. On average, $E_{\mathrm{abs}-370}$ and $E_{\text {abs-880 }}$ values were of $2.07 \pm 0.49$ and $1.53 \pm 0.39$, respectively. As shown in Supplementary Table 1, such elevated $E_{\text {abs }}$ values have

\footnotetext{
'Institut National de l'Environnement Industriel et des Risques, Verneuil-en-Halatte, France; ${ }^{2}$ Laboratoire des Sciences du Climat et de l'Environnement, CNRS-CEA-UVSQ, Gif-surYvette, France; ${ }^{3}$ Laboratory of Atmospheric Chemistry, Paul Scherrer Institute, Villigen PSI, Switzerland; ${ }^{4}$ Centre for Atmospheric Sciences, School of Earth and Environmental

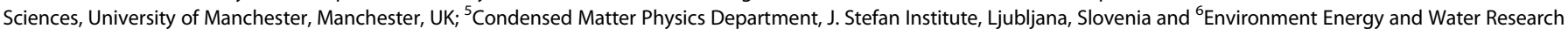
Center, The Cyprus Institute, Nicosia, Cyprus

Correspondence: Yunjiang Zhang (yjanzhang@gmail.com) or Olivier Favez (olivier.favez@ineris.fr)
}

Received: 7 March 2018 Accepted: 13 November 2018

Published online: 21 December 2018 


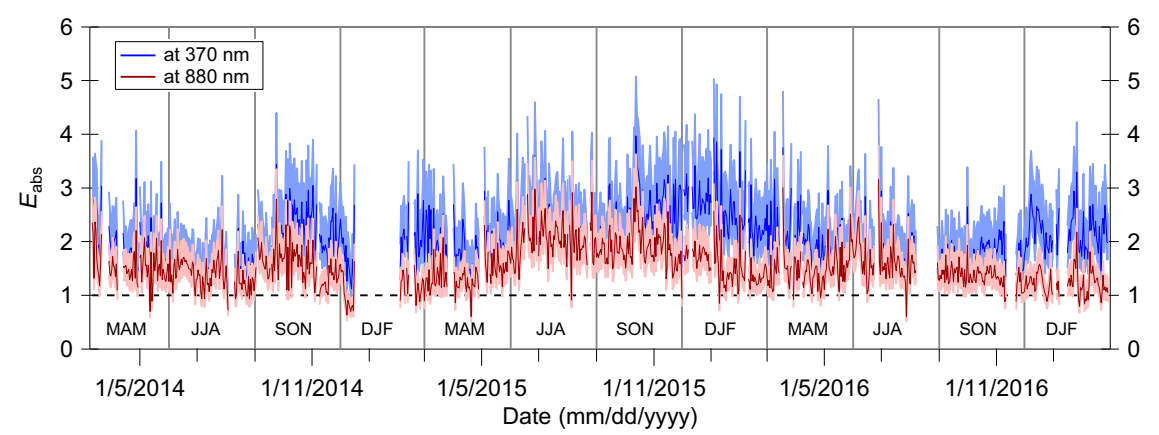

Fig. 1 Time series of daily mean $E_{\mathrm{abs}}$ at $370 \mathrm{~nm}$ and $880 \mathrm{~nm}$ derived from measurements conducted in the period March $2004-M a r c h 2017$. Winter: December-January-February (DJF); Spring: March-April-May (MAM); Summer: June-July-August (JJA); Fall: September-OctoberNovember (SON). The shadow areas refer to $E_{\text {abs }}$ estimated errors when considering maximum $\left(14.2 \mathrm{~m}^{2} \mathrm{~g}^{-1}\right.$ at $370 \mathrm{~nm}$ and $5.7 \mathrm{~m}^{2} \mathrm{~g}^{-1}$ at $880 \mathrm{~nm})$ and minimum $\left(9.4 \mathrm{~m}^{2} \mathrm{~g}^{-1}\right.$ at $370 \mathrm{~nm}$ and $3.9 \mathrm{~m}^{2} \mathrm{~g}^{-1}$ at $880 \mathrm{~nm}$ ) MAC $\mathrm{Mncoated}_{\text {values (Methods) }}$

been previously observed at other locations during short-term campaigns (e.g., 1.40 in London, $\mathrm{UK}^{7}$ or values ranging from 1.22 to 2.25 at various Asian sites ${ }^{19-23}$ ). They are also higher than the mean 1.06 value obtained by Cappa et al. $(2012)^{6}$ from two shortterm measurement campaign in California, USA, potentially underestimating lensing-effect absorption enhancement due to rather low thermodenuder temperature and inefficient removal of low-volatile coating components. ${ }^{11,12}$

As expected, $E_{\text {abs-370 }}$ was systematically higher than $E_{\text {abs- } 880}$ at wintertime, due to the influence of $\mathrm{BrC}$ from residential wood burning emissions. ${ }^{24,25}$ This wavelength dependence was confirmed by the investigation of seasonal frequency distribution of $E_{\text {abs }}$ daily values. As presented in Fig. 2 a, in winter, probability density functions (PDF) centered at values ranging from $1.30 \pm$ 0.01 to $2.25 \pm 0.02$, respectively for 880 and $370 \mathrm{~nm}$. More surprisingly, in summer, differences in $E_{\text {abs }}$ between ultraviolet and near-infrared regions were very low, if not negligible (Fig. 1). During this season, PDF centered at $E_{\text {abs }}$ values of about 1.6 for each wavelength comprised between 470 and $950 \mathrm{~nm}$, and only shifted to $1.75 \pm 0.03$ for $370 \mathrm{~nm}$ (Fig. 2a). These observations indicated a major influence of the lensing effect on $E_{\text {abs }}$ even at ultraviolet wavelengths, during the warm season.

A well-marked year-to-year $E_{\text {abs }}$ variation could also be observed. For example, summertime $E_{\mathrm{abs}-880}$ (and $E_{\mathrm{abs}-370}$ ) values were strikingly higher in 2015 compared to the previous and the following years (Fig. 1). These fluctuations are expected to be related to variations of the thickness and/or the chemical composition of the BC coating structures, as discussed hereafter.

Aerosol mass spectrometry allowed for the measurement of submicron major chemical species (i.e., nitrate, sulfate, ammonium and organic aerosols) followed by the source apportionment of the different organic fractions (Methods and Supplementary Figs. 1 and 2). As shown in Fig. 2b, contrasted seasonal chemical fingerprints-similar to those observed during previous studies at the same location ${ }^{14,26}$ - were obtained. The winter season was mainly influenced by ammonium nitrate and primary organic aerosols (POA), whereas SOA represented the overwhelming fraction ( $52 \%$ on average) of submicron non-refractory aerosols in summer. Noteworthy, elevated wintertime POA contribution was mainly due to biomass burning emissions (Supplementary Fig. 2), again suggesting the major influence of residential wood burning on $\mathrm{BrC}$ absorption during the heating season.

The contribution of each chemical fraction to $E_{\text {abs-880 }}$ was then evaluated by multivariate linear regression analysis (Methods). Results obtained from this analysis are provided in Supplementary Table 2 and illustrated by Supplementary Fig. 3. They clearly indicated SOA components as the main responsible for the lensing effect, while neither the inorganics nor the POA fractions displayed a statistically significant influence on $E_{\text {abs, }}$ fractions. Further, the more oxidized oxygenated organic aerosols (MO-
OOA) were found to have a much higher impact on $E_{\text {abs }}$ than lessoxidized OOA (LO-OOA). The investigation of OA mass spectra allowed enlightening this major role of highly oxidized SOA on $E_{\text {abs. }}$. The amount of $f_{44}$ (namely, the contribution of $\mathrm{m} / \mathrm{z} 44-$ corresponding to $\mathrm{CO}_{2}{ }^{+}$aerosol mass fragment-to the total OA signal) is commonly considered as an indicator of atmospheric aging. 27,28 This parameter followed the same variations than $E_{a b s-}$ 880 throughout the studied period (Supplementary Fig. 4). As presented in Fig. 3a, a well-defined 'triangle plot' could also be generated by plotting $f_{44}$ as a function of $f_{43}$ (indicative of low oxidized SOA), with a gradual increase of $E_{\text {abs- } 880}$ values during the evolution from less to more oxidized OA. In addition, data points corresponding to highest $E_{\mathrm{abs}-880}$ values clustered with the highest SOA-to-secondary inorganic aerosols ratios, confirming the dominating influence of SOA against other possible coating compounds.

These results implied that a large fraction of SOA was internally mixed with $\mathrm{BC}$, due to the aging of primary emissions via (photo-) chemical processes. Evidences to support this hypothesis have been obtained from various measurements. The filter-loading parameter calculated by the dual-spot Aethalometer software was first used as a proxy of the coating thickness, allowing for differentiation between freshly-emitted and processed particles. ${ }^{29}$ As shown in Supplementary Fig. 5, a clear seasonal cycle could be observed for this parameter, with very low values obtained from the end of spring to early fall, indicating the predominance of coated particles during this period of the year. $E_{\text {abs-880 }}$ was also plotted as a function of the ratio between SOA and $\triangle C O$ (with $\Delta \mathrm{CO}=$ total $\mathrm{CO}$-background $\mathrm{CO}$ ), considered as a surrogate of the photochemical age (Methods). ${ }^{3,31} E_{\text {abs-880 }}$ was then found to increase rapidly with $[\mathrm{SOA}]-\mathrm{to}-[\Delta \mathrm{CO}]$ ratio higher than 30 , especially in summer (Fig. 3b), also suggesting that the observed lensing effect was mainly driven by SOA formation through atmospheric photochemical processes in internal mixing with BC. As shown in Supplementary Fig. 6 , highest BC concentrations were associated with winds from the North and Northeastern sectors, i.e., with emissions from the Paris area and/or densely populated regions further away (such as North of France, Benelux, Germany, Poland...). Considering well-marked diel cycles of the absorption coefficient $\left(b_{\mathrm{abs}}\right)$ at $880 \mathrm{~nm}$, especially during week-days (Supplementary Fig. 7), a predominant influence of rather local emissions is expected, which would imply rapid SOA formation processes in the Paris plume and at regional scale. Such findings can be supported by previous studies reporting intense SOA production along with anthropogenic emissions, ${ }^{32,33}$ especially in summer.

The core-shell Mie theory, commonly used in climate models, ${ }^{1}$ was additionally applied to simulate lensing-driven BC absorption enhancement (Methods). To do so, observationally-constrained parameters for model calculations were defined assuming that secondary aerosols were fully present within BC coatings 


\section{a}
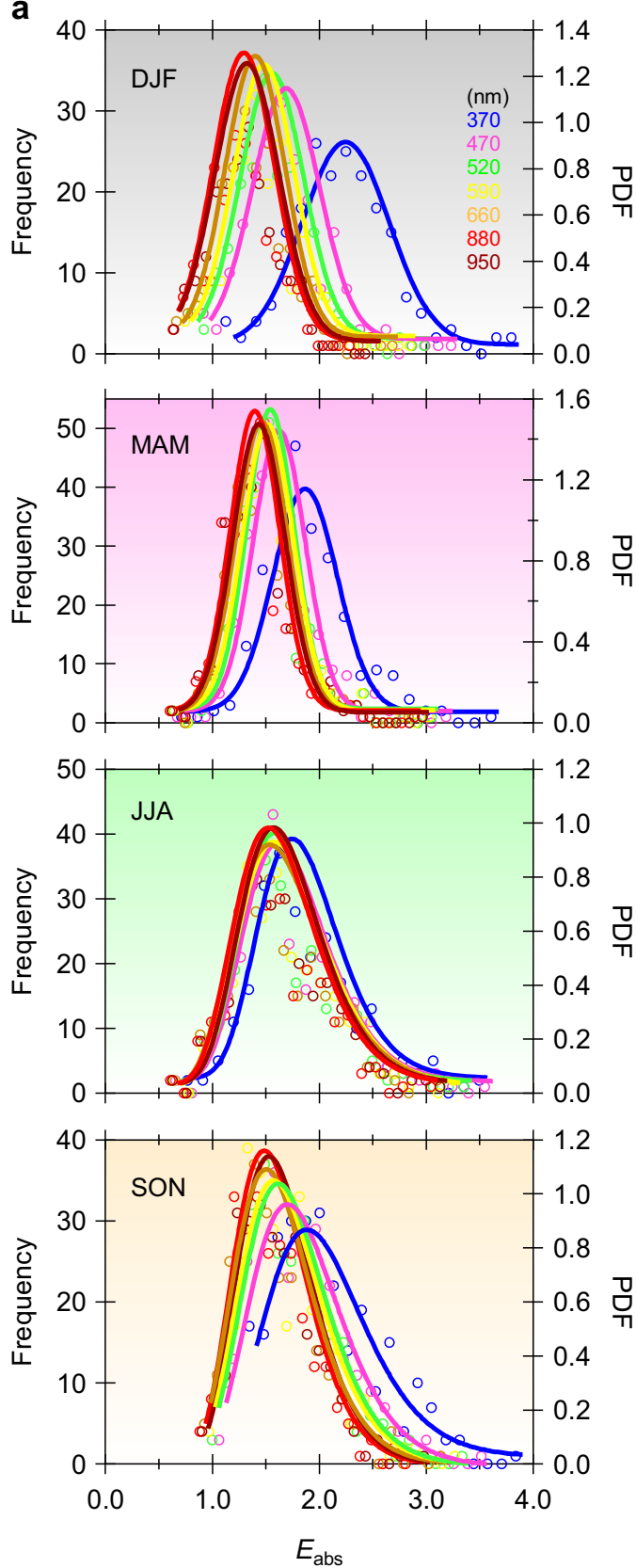

b
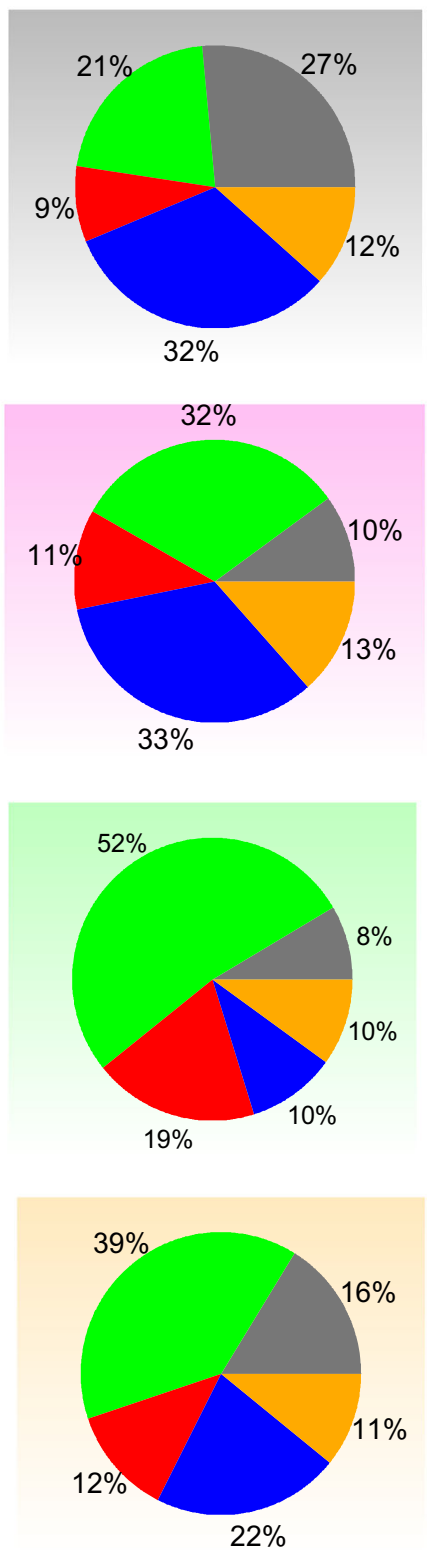

$\mathrm{POA} \mathrm{SOA} \mathrm{SO} \mathrm{SO}_{3} \mathrm{NOH}_{4}$

Fig. 2 Seasonal patterns of wavelength-dependent $E_{\mathrm{abs}}$ and chemical composition. a Frequency distributions of daily $E_{\mathrm{abs}}$ values in Winter: December-January-February (DJF); Spring: March-April-May (MAM); Summer: June-July-August (JJA); Fall: September-October-November (SON). Sample frequencies are shown as hollow circle points, with the curves (solid lines) corresponding to the probability density functions (PDF). b Averaged seasonal relative contributions of chemical fractions to total non-refractory submicron aerosol loadings

(Supplementary Figs. 8 and 9). This assumption was made to evaluate a maximum threshold for the influence of SOA on $E_{\mathrm{abs}}$. An excellent overall agreement was obtained between measurements and model outputs for the highest $f_{44}$ values (Supplementary Fig. 9), when SOA largely dominated other possible coating materials (Supplementary Fig. 10). These results further confirmed the predominance of SOA as internally mixed with BC-containing particles during the summer and fall seasons.

Model calculations were finally used to assess the sensitivity of the influence of SOA and sulfate coatings on $E_{\mathrm{abs}}$ (Methods), both species being considered as the most efficient ones for $B C$ absorption enhancement at the global scale., ${ }^{2,34}$ Results are illustrated by Fig. 4 in the form of a conceptual diagram for $E_{\text {abs }}$ quantification as a function of SOA-to-sulfate mixing ratios when the entire secondary aerosol loadings may be considered as internally mixed with BC. As mentioned above, outputs of such model calculation were globally consistent with observations for the highest $f_{44}$ values (i.e., $>0.25$ ) in summer and fall. Moreover, $E_{\text {abs }}$ appeared to be more sensitive to SOA than to sulfate loadings in the conditions of our study. For instance, starting from typical SOA and sulfate concentrations of $3.0 \mu \mathrm{g} \mathrm{m}^{-3}$ and $0.8 \mu \mathrm{g} \mathrm{m}^{-3}$, respectively, modeled $E_{\text {abs }}$ value would increase from about 2.0 to about 2.3 with the doubling of SOA concentrations, while it would remain approximately constant in case of the doubling of sulfate concentrations (Fig. 4). These results were assessed as indicative of SOA-limited regime for $E_{\text {abs }}$ variations computed in the frame of the present study. 

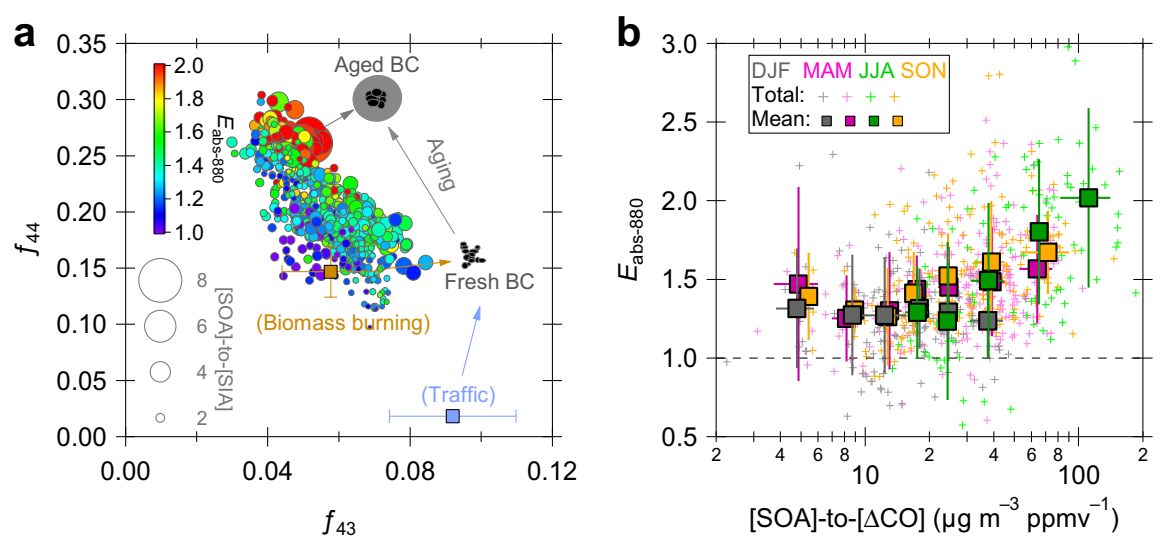

Fig. $3 E_{\text {abs- } 880}$ as a function of atmospheric aging. a $E_{a b s}$ evolution associated with organics aging as a relationship between $f_{44}$ and $f_{43}$. The size of the points is scaled by [SOA]-to-[SIA] ratio, where SIA is the sum of secondary inorganic aerosols (i.e., sulfate, nitrate and ammonium). Two data points (solid square along with standard derivation) relative to primary sources were retrieved from HOA and BBOA mass spectra. $\mathbf{b}$ Observed $E_{\mathrm{abs}}$ as a function of the ratio of $[\mathrm{SOA}]-$ to- $[\Delta \mathrm{CO}]$, a surrogate for the SOA formation and photochemical age, in winter: DJF; spring: MAM; summer: JJA; and fall: SON

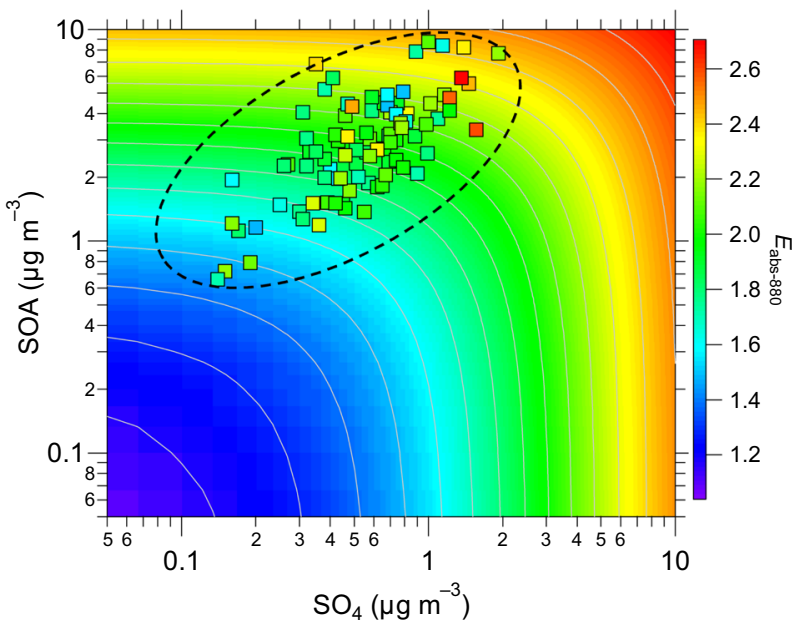

Fig. 4 Conceptual simulation of $E_{\text {abs }}$ due to the lensing effect. The result is predicted from observationally constrained core-shell Mie calculations. Dashed-line region refers to observed mass ratio ranges between SOA and sulfate $\left(\mathrm{SO}_{4}\right)$ under high $f_{44}$ levels. The color of those solid square points is scaled by observed $E_{\mathrm{abs}}$ values at $880 \mathrm{~nm}$

Sensitivity analysis was performed to assess the influence of the considered $\mathrm{BC}$ core size on obtained results. To do so, calculations were achieved for $B C$ core size of $100 \mathrm{~nm}, 120 \mathrm{~nm}$, and $150 \mathrm{~nm}$, which did not significantly affect the model outputs (Supplementary Fig. 8a). Additional sensitivity tests were then achieved on the influence of the coating thickness parameter, applying calculations to 3 different types of aerosol coating mixtures: (1) $100 \%$ of the total secondary aerosols and $100 \%$ of the total non-refractory primary aerosols (i.e., POA), (2) $100 \%$ of the total secondary aerosols and $50 \%$ of the total POA, and (3) $50 \%$ of the total secondary aerosols and $50 \%$ of the total POA. As presented in Supplementary Fig. 8b, no significant change was observed when varying the amount of POA potentially mixed with BC. Discrepancies were more obvious when varying the fraction of secondary aerosols being embedded with $\mathrm{BC}$. When considering that $100 \%$ of the measured secondary aerosols species were internally mixed with $\mathrm{BC}$, the model globally over-estimated $E_{a b s}$ values, except during the summer-fall seasons where an average ratio close to 1 could be obtained between model outputs and measurements (see also Supplementary Fig. 9). When considering that only $50 \%$ of secondary aerosols were internally mixed with
BC, the model systematically under-estimated observations done during the summer and fall seasons. Results of these sensitivity tests seem to confirm that approximately $100 \%$ of secondary aerosols could be considered as part of BC coating (and BCcontaining particles could be considered as fully-aged) during the warm period, and especially for highest $f_{44}$ levels.

\section{DISCUSSION}

In the present study, we notably made use of simple but robust measurement techniques to investigate BC absorption enhancement and its main chemical agents over long-term period. Further similar studies will shortly be possible at other sites around the world in the frame of developing research networks, such as ACTRIS in Europe. Here, we demonstrated the major interest of pursuing and reinforcing EC monitoring along with absorption measurements in such program, the combination of both parameters allowing for multiyear $E_{\text {abs }}$ investigation.

A clear limitation of indirect $E_{\text {abs }}$ quantification using filterbased absorption photometer measurements, as performed here, relies on relatively high uncertainties, assessed to be on the order of $50 \%$ (Methods). ${ }^{20,35}$ Nevertheless, values derived from the present dataset somehow confirm the 1.5 value roughly and commonly used within global scale climate models. ${ }^{1}$

Furthermore, our findings infer that considering the yearly cycle of photochemical SOA production should help better assessing seasonal influences of $B C$ global warming. They also suggest that efficient strategies for the reduction of SOA burden in the atmosphere-including abatement of volatile organic compounds emissions-could significantly weaken the $B C$ radiative forcing, at least over the Paris area. They could further be considered as an accurate global scale perspective for the near-future atmosphere, with decreasing ammonium sulfate loadings due to ongoing reduction of $\mathrm{SO}_{2}$ emissions. ${ }^{36}$

\section{METHODS}

In this section, we describe the methodologies used for this study, including information on field measurements, data treatment procedures and modeling computations. This description starts with the instrumentation used to investigated aerosol light absorption properties and chemical composition. $E_{\text {abs }}$ has been calculated based on daily EC concentrations and uncoated-BC theoretical MAC value. Receptor model analysis was furthermore achieved to identify and quantify the main organic aerosol fractions. The potential influence of the different aerosol chemical species (inorganic compounds and various $O A$ fractions) on $E_{\text {abs }}$ could then be investigated, notably using multivariate linear regression analysis. Finally, 
the core-shell Mie theory was applied to simulate the optical properties of BC-containing particles.

\section{Measurements}

Long-term in-situ direct measurements were carried out from March 2014 to March 2017 at the SIRTA facility (Site Instrumental de Recherche par Teledetection Atmospherique, www.sirta.fr), ${ }^{37}$ as part of the ACTRIS program (Aerosols, Clouds, and Traces gases Research InfraStructure network, www.actris.eu).

Aerosol light absorption was measured at 7 different wavelengths (namely 370, 470, 520, 590, 660, 880, and $950 \mathrm{~nm}$ ) using an AE33 Aethalometer (Magee Scientific) equipped with a $\mathrm{PM}_{25}$ sampling head. This recently developed instrument is extensively described by Drinovec et al. $^{38}$ Briefly, it is based on the measurement of light attenuation by airborne particles collected onto a fiber filter tape. $b_{\text {abs }}$ (in $\mathrm{m}^{-1}$ unit) is retrieved from attenuation measurements $\left(b_{\mathrm{ATN}}\right)$ at each wavelength, following Eq. 1:

$b_{\mathrm{abs}}=\frac{b_{\text {ATN }}}{C}$

where $C$ represents the overall filter multiple-scattering parameter. In accordance with recommendations within the ACTRIS program for AE31 model $^{35}$ and considering differences between AE31 and AE33 parametrizations, a $C$ value of 2.57 was applied here at each wavelength. ${ }^{39}$ Furthermore, within the AE33 model, aerosols are sampled on 2 filter spots at different flowrates $\left(3.31 \mathrm{~min}^{-1}\right.$ and $1.7 / \mathrm{min}^{-1}$, respectively, in the present study), allowing for automatic correction of artefacts related to loading effects. This automatic correction is based on the calculation of wavelength-dependent compensation parameters $(k)$, varying with the nature of sampled aerosols. Supplementary Fig. 5 shows the monthlyaveraged variation obtained in the present study for this compensation parameter at $880 \mathrm{~nm}$. High $k$ values are assessed to indicate freshlyemitted aerosols, whereas low $k$ values reflect the predominance of aged/ coated BC-containing aerosols. ${ }^{29}$ Noteworthy, the influence of relative humidity (RH) was minimized in the present study thanks to a drier system installed upstream of the AE33 inlet.

Continuous monitoring of the submicron non-refractory aerosol species $\left(N R-P M_{1}\right)$, including organics, sulfate, nitrate, ammonium and chloride, was achieved using an Aerosol Chemical Speciation Monitor (ACSM, Aerodyne Research Inc.) with a $\sim 30$ min time-resolution. The measurement principle and accuracy of this instrument are fully described elsewhere. ${ }^{40}$ Briefly, submicron aerosols are sampled through an aerodynamic lens. The resulting particle beam is focused under vacuum onto a vaporizer heated at $600{ }^{\circ} \mathrm{C}$. Non-refractory aerosols are then transformed into a molecular plume, which is ionized, before quantification using a quadrupole mass spectrometer. Aerosol loadings were calculated here using a standard data analysis software (ACSM local, v 1.5.3.0).

EC mass concentrations were obtained by offline analysis of $\mathrm{PM}_{2.5}$ daily filters, following ACTRIS procedures. ${ }^{35}$ These filters were collected using a Partisol 2025 low volume sampler (Thermo Scientific) at a flow rate of $1 \mathrm{~m}^{3} \mathrm{~h}^{-1}$. Filter samples of $1 \mathrm{~cm}^{2}$ were punched from the filters and then analyzed using a Sunset Lab. OC/EC analyzer, using the EUSAAR-2 thermooptical protocol. ${ }^{41}$ Regular filter blank analyses always showed blank EC values below detection limit.

Finally, a chromatograph (PP1, Peak Performer) with a reduced gas detector (RGD) was used to measure $\mathrm{CO}$ by reduction of mercuric oxide and detection of mercury vapor by UV absorption. $\mathrm{CO}$ concentrations were used to calculate the $[\mathrm{SOA}]$-to- $[\Delta \mathrm{CO}]$ ratio. In this calculation, datapoints below the 5th and upper the 95th percentiles were excluded to minimize the influence of outliers, and CO background concentrations were determined as the mean seasonal values of $5 \%$ lowest $\mathrm{CO}$ concentrations, as proposed by Takegawa et al. (2006). ${ }^{31}$

\section{Calculation of absorption enhancement}

At a given wavelength, $E_{\mathrm{abs}}$ values is commonly calculated as the ratio between the observed mass absorption cross section (MAC) to the theoretical uncoated MAC of absorbing aerosols, ${ }^{20,23,35,42}$ following Eq. 2:

$$
E_{\mathrm{abs}}^{\lambda}=\frac{M A C_{\mathrm{obs}}^{\lambda}}{M A C_{\text {uncoated }}^{\lambda}}
$$

Where MAC is usually obtained as the ratio of the absorption coefficient to
EC mass concentration ${ }^{20,23,35,42}$ following Eq. 3:

$\mathrm{MAC}_{\mathrm{obs}}^{\lambda}=\frac{b_{\mathrm{abs}}^{\lambda}}{\mathrm{EC}}$

In the present study, absorption coefficients were retrieved from AE33 online measurements, while EC was measured on daily filters. Absorption coefficients were then averaged on $24 \mathrm{~h}$-period prior to $M A C_{o b s}$ value calculation.

$M A C_{\text {uncoated }}$ values were calculated at each wavelength (Supplementary Table 3) assuming the widely used reference value of $7.5 \pm 1.2\left(\mathrm{~m}^{2} \mathrm{~g}^{-1}\right)$ at $550 \mathrm{~nm}$ and an Absorption Angstrom Exponent (AAE) value of $1,{ }^{43}$ following Eq. 4:

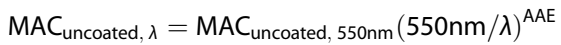

The choice of $M A C_{\text {uncoated }}$ is crucial for the calculation of $E_{\text {abs }}$ based on measurements. Uncertainties related to this choice, was assessed as follows:

i. considering that this uncertainty is at least of $1.2 \mathrm{~m}^{2} \mathrm{~g}^{-1}$ at $550 \mathrm{~nm}^{43}$ and calculating minimum uncertainty at each wavelength using this value and an AAE value of 1 ;

ii. considering the $y$-intercept obtained when plotting observed $M A C$ value as a function of the ratio of total NR-PM 1 to EC $\left(R_{\text {NR-PM1-EC }}\right)$ for datapoints corresponding to each season (Supplementary Fig. 11);

iii. assessing the uncertainty linked to the used AAE value.

As shown in Supplementary Fig. 11, results obtained from the " $y$ intercept method" gave seasonal values of $4.36 \pm 0.62 \mathrm{~m}^{2} \mathrm{~g}^{-1}$ (DJF), $5.68 \pm$ $0.43 \mathrm{~m}^{2} \mathrm{~g}^{-1}$ (MAM), $4.54 \pm 0.70 \mathrm{~m}^{2} \mathrm{~g}^{-1}$ (JJA), and $5.33 \pm 0.38 \mathrm{~m}^{2} \mathrm{~g}^{-1}$ (SON) at $880 \mathrm{~nm}$. The uncertainty of the chosen AAE value was estimated from AE33 data measured in a tunnel environment in urban Paris during a 3week field campaign in Autumn 2012 (courtesy of J. Sciare). An average AAE value of 0.99 (over the $370-950 \mathrm{~nm}$ wavelength region) was obtained from this tunnel experiment, with standard deviation of \pm 0.06 . Results obtained from the investigation of vehicle exhaust particles during this campaign can be assessed as representative of fresh BC measurements using AE33 in the Paris area. The latter standard deviation was then considered as the AAE uncertainty in the present study. Putting everything together, the range of possible deviation for $M A C_{\text {uncoated values could }}$ eventually be calculated at each wavelength, as illustrated by Supplementary Fig. 12 and summarized in Supplementary Table 3. According to those calculations, an uncertainty of $\pm 20 \%$ was obtained for the $M A C_{\text {uncoated }}$ value at the $880 \mathrm{~nm}$ wavelength used in the present study.

Other uncertainties possibly influencing the calculation of $\mathrm{MAC}_{\mathrm{obs}}$ are mainly linked to EC measurements and to the validity of the $C$ value chosen for the determination of absorption coefficients (Eq. 1). Depending on the thermal protocol used for EC measurements, discrepancies up to $40 \%$ can be obtained for samples collected in France. ${ }^{44}$ Regarding $C$, this parameter is not constant over time and is notably influenced by the socalled "cross-sensitivity to scattering" effect, ${ }^{38}$ which can be parametrized modifying Eq. 1 as follows:

$b_{\text {ATN }}=C \cdot b_{\text {abs }}+m_{\mathrm{s}} \cdot b_{\text {scatt }}$

where $b_{\text {scatt }}$ is the scattering coefficient and $m_{\mathrm{s}}$ is describing the additional attenuation due to the presence of scattering material in the filter. In the present study, $b_{\text {scatt }}$ were available thanks to collocated nephelometer (Ecotech, model M9003) measurements at $450 \mathrm{~nm}$. When using a maximum $m_{\mathrm{s}}$ value of $0.02{ }^{38}$ a $10 \%$ uncertainty on $b_{\text {abs }}$ coefficients was obtained (Supplementary Fig. 13). Moreover, based on previous studies, ${ }^{39,45-47}$ we estimated the uncertainty in $C$ due to its possible wavelength dependence to be of $4 \%$ in the $370-950 \mathrm{~nm}$ region.

It should be noted that errors in EC and $C$ are expected to be already included the "y-intercept method" used for the estimation of MAC uncoated uncertainty based on measurements (see above and Supplementary Fig. 11). Nevertheless, when applying the propagation of errors to $M A C_{\text {uncoated }}$ $E C$, and $C$ parameter, an overall uncertainty of $48 \%$ was obtained for the determination of $E_{\text {abs }}$ which is in good agreement with uncertainties assessed by previous studies. ${ }^{20,35}$

\section{OA source apportionment}

The various $O A$ fractions were identified and quantified using positive matrix factorization (PMF) ${ }^{48}$ applied to the OA mass spectra measured by ACSM, using the Source Finder toolkit along with multi-linear engine (ME2) algorithm. ${ }^{49,50}$ The input data matrices, including $\mathrm{m} / \mathrm{z}$-based species and uncertainties, were pretreated following procedures recommended by 
Ulbrich et al. ${ }^{51} \mathrm{~m} / \mathrm{z}=12$ and $\mathrm{m} / \mathrm{z}>100$ were notably removed for the PMF analysis because of their large uncertainties. The 3y-long OA data matrix was divided into 7 different PMF analyses, according to the intervals between (relative) ion efficiency calibrations.

A series of 4-factor solutions was found to better described organic aerosol variations of our long-term dataset. OA factors includes two POA factors and two SOA factors, corresponding to averaged mass spectra presented in Supplementary Figs. 1a-d. POA factors, i.e., hydrocarbon-like $\mathrm{OA}(\mathrm{HOA})$ and biomass burning $\mathrm{OA}(\mathrm{BBOA})$, were constrained using the socalled $a$-value approach. ${ }^{50}$ Reference mass spectra previously determined at SIRTA by Fröhlich et al. ${ }^{52}$ were employed as anchor profiles, using $a$ value range of $0.1-0.4$, for both of these POA factors, as recommended by Crippa et al. ${ }^{53}$ The two SOA factors, i.e., a less oxidized oxygenated OA (LO$\mathrm{OOA}$ ) and a more oxidized oxygenated OA (MO-OOA) were left unconstrained.

Diel cycles of the four factors are presented by season in Supplementary Figs. 1e-h. The HOA factor displayed two evident peaks associated with the morning and evening traffic rush hours throughout the year (Supplementary Fig. 1e), as already shown previously at the same site. ${ }^{14,26}$ As expected BBOA factor showed highest concentrations during the winter season, while it is barely significant in summer. Well-defined diel cycles were obtained for this factor, with highest levels during nighttime (Supplementary Fig. 1f), which can be linked to strong residential wood burning emissions $^{24-26}$, as well as variations of the boundary layer dynamic height.

LO-OOA diel variations showed highest concentrations during nighttime in winter, spring and fall (Supplementary Fig. 1g), partly related to the presence of semi-volatile $O A{ }^{27,28}$ Along with a similar nighttime maximum, a slight afternoon increase could be observed in summer, likely due to SOA formation mechanisms. ${ }^{54}$ By definition, MO-OOA mass spectrum displayed lower $f_{43}$ (fraction of $m / z 43$ in total OA signal) and higher $f_{44}$ (fraction of $\mathrm{m} /$ $z 44$ in total OA signal) values than MO-OOA. In summer, this MO-OOA factor also presented a noticeable afternoon increase (Supplementary Fig. $1 \mathrm{~h}$ ), for the possible same reason than LO-OOA (although photochemical formation mechanisms may be different in both cases). In the three other seasons, slight increase of MO-OOA concentrations were observed at nighttime, which is likely to be due to atmospheric dilution effect and/or reduced photochemical processes.

Influences of the chemical fractions on $E_{\text {abs }}$

The multivariate linear regression (MLR) analysis allowing for elucidating the influence of each chemical species on $E_{\text {abs }}$ was applied following Eq. 6:

$$
\begin{aligned}
{\left[E_{\mathrm{abs}-880}\right]=} & \beta_{0}+\beta_{1} \times[\mathrm{HOA}-\text { to }-\mathrm{EC}]+\beta_{2} \times[\mathrm{BBOA}-\text { to }-\mathrm{EC}]+\beta_{3} \times \\
& {[\mathrm{MO}-\mathrm{OOA}-\text { to }-\mathrm{EC}]+\beta_{4} \times[\mathrm{LO}-\mathrm{OOA}-\text { to }-\mathrm{EC}]+\beta_{5} \times } \\
& {\left[\mathrm{SO}_{4}-\text { to }-\mathrm{EC}\right]+\beta_{6} \times\left[\mathrm{NO}_{3}-\text { to }-\mathrm{EC}\right] }
\end{aligned}
$$

where $\beta_{\mathrm{i}}$ are the regression coefficients and the daily-averaged ratios of the chemical fractions to EC are the dependent variables.

As shown in Supplementary Fig. $14 \mathrm{a}$, observed $E_{\text {abs }}$ values were following normal distribution, except for a few datapoints. To reduce the influence of outliers, datapoints lower than the 5th and upper than the 95th percentiles ( $N=33$, corresponding to $4 \%$ of the total available data) were excluded from this MLR analysis. When checking for possible collinearity between the variables, each of the obtained Pearson correlation coefficients were below 0.5 (with a maximum value of 0.47 , $P<0.001$, Supplementary Table 4). This suggested that collinearity between variables was unlikely, which was also confirmed by the investigation of the condition index values (Supplementary Table 5).

Results of this MLR analysis are detailed in Supplementary Table 2, indicating that only MO-OOA and LO-OOA had a statistically significant influence on $E_{\text {abs }}$ (with $p$-values $<0.0001$ ). The accuracy of this analysis was confirmed by the fact that standardized residuals displayed a normal distribution (Supplementary Fig. 14b), as well as a good correlation with

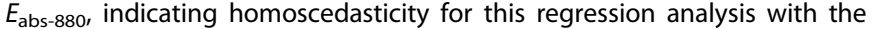
chosen variables (Supplementary Fig. 14c). Moreover, reconstructed $E_{\text {abs- }}$ 880 values had a statistically significant correlation $(P<0.001$ and $r=0.542)$ with the observed ones. It should also be noted that similar results were obtained when considering the $950 \mathrm{~nm}$ wavelength (Supplementary Fig. 15).

An offset of 1.32 was obtained from this regression analysis. This was assessed as reflecting discrepancies between the used $M A C_{\text {uncoated }}$ value of 4.7 and the highest value (5.7) of the intercepts obtained for each season from the scatterplot between observed MAC values and the ratio of $\mathrm{NR}-\mathrm{PM}_{1}$ to EC (Supplementary Fig. 11). When using the latter value of 5.7, the offset of the regression analysis felled down to a value (1.10) close to 1, while no other major difference was obtained (Supplementary Fig. 3b, Supplementary Table 6).

\section{Core-shell Mie calculation}

The core-shell Mie theory was used here for theoretical calculations of $E_{\mathrm{abs}}$ due to the lensing effect. We first assume that internally mixed $B C$ exists as a core-shell mode, i.e., the spherical $B C$ core is concentrically embedded well in the "shell" of non-BC material. Meanwhile, the non-BC coating mass was considered to be homogenously distributed among all BC-containing particles. The median size of $B C$ core was assumed here to be of $120 \mathrm{~nm}$, as a best-guess value based on results from previous studies in Paris and nearby London. ${ }^{15,55,56}$ The relative coating thickness, i.e., an average size ratio between total particle $\left(r_{\text {particle }}\right)$ to core $\left(r_{\text {core }}\right)$, of core-shell BC particles was thus calculated following Eq. $7^{6}$ :

$\frac{r_{\text {particle }}}{r_{\text {core }}}=\sqrt[3]{\frac{m_{\text {coating }}}{\rho_{\text {coating }}} \frac{\rho_{\mathrm{BC}}}{m_{\mathrm{BC}}}+1}=\sqrt[3]{R_{\mathrm{BC}} \frac{\rho_{\mathrm{BC}}}{\rho_{\text {coating }}}}$,

where $r_{\text {particle }}$ and $r_{\text {core }}$ refer to radius of entire particle and $\mathrm{BC}$ core, respectively. $m_{\mathrm{BC}}$ and $m_{\text {coating }}$ are the measured mass concentrations of $\mathrm{BC}$ and non-BC coatings, respectively. The particle density $(\rho)$ is relative to each species, with $p_{\mathrm{BC}}=1.8\left(\mathrm{~g} \mathrm{~cm}^{-3}\right), \rho_{\text {inorganics }}=1.7\left(\mathrm{~g} \mathrm{~cm}^{-3}\right), p_{\mathrm{HOA}}=1.0(\mathrm{~g}$ $\left.\mathrm{cm}^{-3}\right), \rho_{\mathrm{BBOA}}=1.2\left(\mathrm{~g} \mathrm{~cm}^{-3}\right), \rho_{\mathrm{LO}-\mathrm{OOA}}=1.4\left(\mathrm{~g} \mathrm{~cm}^{-3}\right)$ and $\rho_{\mathrm{MO}-\mathrm{OOA}}=1.6(\mathrm{~g}$ $\left.\mathrm{cm}^{-3}\right){ }^{6,57} \mathrm{~A} \mathrm{BC}$ core refractive index of $n_{\text {core }}=1.85+0.711^{42}$ and coating refractive index of $n_{\text {coating }}=1.5+0 \mathrm{i}^{8}$ were used for the BC core and non$B C$ shell, respectively.

Computed $E_{\text {abs }}$ could then be evaluated following Eq. 8:

$E_{\text {abs-core-shell }}^{\lambda}=\frac{M A C_{\text {core-shell }}^{\lambda}}{M A C_{\text {uncoated }}^{\lambda}}$

\section{Code availability}

The code used to perform the PMF analysis can be accessed via https:// www.psi.ch/lac/sofi-sourcefinder (last access: 5 November 2018). ${ }^{50}$ The code used to perform core-shell Mie calculation can be accessed via http:// cpc.cs.qub.ac.uk/summaries/AEEY_v1_0.html (last access: 5 November 2018)..$^{58}$

\section{DATA AVAILABILITY}

All data needed to evaluate the conclusions in the paper are present in the paper and/or the Supplementary Information. Additional data related to this paper may be requested from the authors.

\section{ACKNOWLEDGEMENTS}

This work is part of the COLOSSAL COST action CA16109. It has also been supported by the EU-FP7 and H2020 ACTRIS projects (grant agreements no. 262254 and 654109), by the French Research Council (CNRS), as well as by the French ministry of Environment and the reference laboratory for air quality monitoring (LCSQA). The authors gratefully thank François Truong and Nicolas Bonnaire (LSCE), as well as Robin Aujay (INERIS), for taking care of aerosol filter samples and monitors. CO measurements are part of the SNO RAMCES/ICOS-France monitoring network coordinated by LSCE/OVSQ. Y.Z. acknowledges the China Scholarship Council (CSC) for PhD scholarship. Authors thanks the RAMCES research group, and especially Martina Schmidt, Camille Yver Kwok and Ayche Orgun, for providing this data.

\section{AUTHOR CONTRIBUTIONS}

Y.Z., O.F., and A.A. proposed the initial idea. O.F., A.A., and V.G. designed and led the study. Y.Z. conducted the data analyses. J.S. and T.A. provided the field observation. F. C. and A.P. supported the OA source apportionment analyses. D.L. supported the core-shell Mie model calculation. G.M. supported the uncertainty assessment of aerosol absorption measurements. Y.Z. and O.F. interpreted the data, and wrote the manuscript, with inputs from all coauthors. 


\section{ADDITIONAL INFORMATION}

Supplementary information accompanies the paper on the npj Climate and Atmospheric Science website (https://doi.org/10.1038/s41612-018-0056-2).

Competing interests: The authors declare no competing interests.

Publisher's note: Springer Nature remains neutral with regard to jurisdictional claims in published maps and institutional affiliations.

\section{REFERENCES}

1. Bond, T. C. et al. Bounding the role of black carbon in the climate system: a scientific assessment. J. Geophys. Res. 118, 5380-5552 (2013).

2. Jacobson, M. Z. Strong radiative heating due to the mixing state of black carbon in atmospheric aerosols. Nature 409, 695-697 (2001).

3. Zhang, R. et al. Variability in morphology, hygroscopicity, and optical properties of soot aerosols during atmospheric processing. Proc. Natl Acad. Sci. USA 105, 10291-10296 (2008).

4. Lack, D. A. \& Cappa, C. D. Impact of brown and clear carbon on light absorption enhancement, single scatter albedo and absorption wavelength dependence of black carbon. Atmos. Chem. Phys. 10, 4207-4220 (2010).

5. Myhre, G. et al. Radiative forcing of the direct aerosol effect from AeroCom Phase II simulations. Atmos. Chem. Phys. 13, 1853-1877 (2013).

6. Cappa, C. D. et al. Radiative absorption enhancements due to the mixing state of atmospheric black carbon. Science 337, 1078-1081 (2012).

7. Liu, S. et al. Enhanced light absorption by mixed source black and brown carbon particles in UK winter. Nat. Commun. 6, 8435 (2015).

8. Liu, D. et al. Black-carbon absorption enhancement in the atmosphere determined by particle mixing state. Nat. Geosci. 10, 184-188 (2017).

9. Peng, J. et al. Markedly enhanced absorption and direct radiative forcing of black carbon under polluted urban environments. Proc. Natl Acad. Sci. USA 113, 4266-4271 (2016).

10. IPCC. Climate Change 2013: The Physical Science Basis. Contribution of Working Group I to the Fifth Assessment Report of the Intergovernmental Panel on Climate Change. (Cambridge University Press, 2013) https://www.ipcc.ch/report/ar5/wg1/.

11. Jacobson, M. Z. Comment on "Radiative Absorption Enhancements Due to the Mixing State of Atmospheric Black Carbon". Science 339, 393-393 (2013).

12. Cappa, C. D. et al. Response to Comment on "Radiative Absorption Enhancements Due to the Mixing State of Atmospheric Black Carbon". Science 339, 393-393 (2013).

13. Gustafsson, Ö. \& Ramanathan, V. Convergence on climate warming by black carbon aerosols. Proc. Natl Acad. Sci. USA 113, 4243-4245 (2016).

14. Petit, J. E. et al. Two years of near real-time chemical composition of submicron aerosols in the region of Paris using an Aerosol Chemical Speciation Monitor (ACSM) and a multi-wavelength Aethalometer. Atmos. Chem. Phys. 15, 2985-3005 (2015).

15. Laborde, M. et al. Black carbon physical properties and mixing state in the European megacity Paris. Atmos. Chem. Phys. 13, 5831-5856 (2013).

16. Beekmann, M. et al. In situ, satellite measurement and model evidence on the dominant regional contribution to fine particulate matter levels in the Paris megacity. Atmos. Chem. Phys. 15, 9577-9591 (2015).

17. Andreae, M. O. \& Gelencsér, A. Black carbon or brown carbon? The nature of lightabsorbing carbonaceous aerosols. Atmos. Chem. Phys. 6, 3131-3148 (2006).

18. Lack, D. A. et al. Brown carbon and internal mixing in biomass burning particles. Proc. Natl Acad. Sci. USA 109, 14802-14807 (2012).

19. Ueda, S. et al. Light absorption and morphological properties of soot-containing aerosols observed at an East Asian outflow site, Noto Peninsula, Japan. Atmos. Chem. Phys. 16, 2525-2541 (2016)

20. Wu, C., Wu, D. \& Yu, J. Z. Quantifying black carbon light absorption enhancement with a novel statistical approach. Atmos. Chem. Phys. 18, 289-309 (2018).

21. Thamban, N. M., Tripathi, S. N., Moosakutty, S. P., Kuntamukkala, P. \& Kanawade, V. P. Internally mixed black carbon in the Indo-Gangetic Plain and its effect on absorption enhancement. Atmos. Res 197, 211-223 (2017).

22. Wang, Q. et al. Mixing state of black carbon aerosol in a heavily polluted urban area of China: implications for light absorption enhancement. Aerosol Sci. Technol. 48, 689-697 (2014)

23. Cui, X. et al. Radiative absorption enhancement from coatings on black carbon aerosols. Sci. Total Environ. 551-552, 51-56 (2016).

24. Favez, O., Cachier, H., Sciare, J., Sarda-Estève, R. \& Martinon, L. Evidence for a significant contribution of wood burning aerosols to PM2.5 during the winter season in Paris, France. Atmos. Environ. 43, 3640-3644 (2009).

25. Sciare, J. et al. Large contribution of water-insoluble secondary organic aerosols in the region of Paris (France) during wintertime. J. Geophys. Res. 116, D22203 (2011).
26. Petit, J. E. et al. Submicron aerosol source apportionment of wintertime pollution in Paris, France by double positive matrix factorization $\left(\mathrm{PMF}^{2}\right)$ using an aerosol chemical speciation monitor (ACSM) and a multi-wavelength Aethalometer Atmos. Chem. Phys. 14, 13773-13787 (2014).

27. Jimenez, J. L. et al. Evolution of organic aerosols in the atmosphere. Science $\mathbf{3 2 6}$ 1525-1529 (2009).

28. Ng, N. L. et al. Changes in organic aerosol composition with aging inferred from aerosol mass spectra. Atmos. Chem. Phys. 11, 6465-6474 (2011).

29. Drinovec, L. et al. The filter-loading effect by ambient aerosols in filter absorption photometers depends on the coating of the sampled particles. Atmos. Meas. Tech. 10, 1043-1059 (2017).

30. Hu, W. W. et al. Insights on organic aerosol aging and the influence of coal combustion at a regional receptor site of central eastern China. Atmos. Chem. Phys. 13, 10095-10112 (2013).

31. Takegawa, N. et al. Seasonal and diurnal variations of submicron organic aerosol in Tokyo observed using the Aerodyne aerosol mass spectrometer. J. Geophys. Res. Atmos 111, D11206 (2006).

32. Volkamer, R. et al. Secondary organic aerosol formation from anthropogenic air pollution: rapid and higher than expected. Geophys. Res. Lett. 33, L17811 (2006).

33. Moffet, R. C. \& Prather, K. A. In-situ measurements of the mixing state and optical properties of soot with implications for radiative forcing estimates. Proc. Nat Acad. Sci. USA 106, 11872-11877 (2009).

34. Zhu, J. et al. Mechanism of SOA formation determines magnitude of radiative effects. Proc. Natl Acad. Sci. USA 114, 12685-12690 (2017).

35. Zanatta, M. et al. A European aerosol phenomenology-5: climatology of black carbon optical properties at 9 regional background sites across Europe. Atmos. Environ. 145, 346-364 (2016).

36. Krotkov, N. A. et al. Aura OMI observations of regional $\mathrm{SO} 2$ and $\mathrm{NO} 2$ pollution changes from 2005 to 2015. Atmos. Chem. Phys. 16, 4605-4629 (2016).

37. Haeffelin, M. et al. SIRTA, a ground-based atmospheric observatory for cloud and aerosol research. Ann. Geophys. 23, 253-275 (2005).

38. Drinovec, L. et al. The "dual-spot" Aethalometer: an improved measurement of aerosol black carbon with real-time loading compensation. Atmos. Meas. Tech. 8 1965-1979 (2015).

39. Corbin, J. C. et al. Brown and black carbon emitted by a marine engine operated on heavy fuel oil and distillate fuels: optical properties, size distributions, and emission factors. J. Geophys. Res. Atmos. 123, 6175-6195 (2018).

40. $\mathrm{Ng}, \mathrm{N}$. L. et al. An aerosol chemical speciation monitor (ACSM) for routine monitoring of the composition and mass concentrations of ambient aerosol. Aerosol Sci. Technol. 45, 780-794 (2011).

41. Cavalli, F., Viana, M., Yttri, K. E., Genberg, J. \& Putaud, J. P. Toward a standardised thermal-optical protocol for measuring atmospheric organic and elemental carbon: the EUSAAR protocol. Atmos. Meas. Tech. 3, 79-89 (2010).

42. Adler, G., Riziq, A. A., Erlick, C. \& Rudich, Y. Effect of intrinsic organic carbon on the optical properties of fresh diesel soot. Proc. Natl. Acad. Sci. USA 107, 6699-6704 (2010)

43. Bond, T. C. \& Bergstrom, R. W. Light absorption by carbonaceous particles: an investigative review. Aerosol Sci. Technol. 40, 27-67 (2006).

44. Chiappini, L. et al. Clues for a standardised thermal-optical protocol for the assessment of organic and elemental carbon within ambient air particulate matter. Atmos. Meas. Tech. 7, 1649-1661 (2014).

45. Arnott, W. P., Hamasha, K., Moosmüller, H., Sheridan, P. J. \& Ogren, J. A. Towards aerosol light-absorption measurements with a 7-wavelength aethalometer: evaluation with a photoacoustic instrument and 3-wavelength nephelometer Aerosol Sci. Technol. 39, 17-29 (2005).

46. Schmid, O. et al. Spectral light absorption by ambient aerosols influenced by biomass burning in the Amazon Basin. I: comparison and field calibration of absorption measurement techniques. Atmos. Chem. Phys. 6, 3443-3462 (2006).

47. Segura, S. et al. Determination and analysis of in situ spectral aerosol optical properties by a multi-instrumental approach. Atmos. Meas. Tech. 7, 2373-2387 (2014).

48. Paatero, P. \& Tapper, U. Positive matrix factorization: a non-negative factor model with optimal utilization of error estimates of data values. Environmetrics $\mathbf{5}$ 111-126 (1994).

49. Paatero, P. The multilinear engine-a table-driven, least squares program for solving multilinear problems, including the n-way parallel factor analysis model. J. Comput. Graph Stat. 8, 854-888 (1999).

50. Canonaco, F., Crippa, M., Slowik, J. G., Baltensperger, U. \& Prévôt, A. S. H. SoFi, an IGOR-based interface for the efficient use of the generalized multilinear engine (ME-2) for the source apportionment: ME-2 application to aerosol mass spectrometer data. Atmos. Meas. Tech. 6, 3649-3661 (2013).

51. Ulbrich, I. M., Canagaratna, M. R., Zhang, Q., Worsnop, D. R. \& Jimenez, J. L. Interpretation of organic components from Positive Matrix Factorization of aerosol mass spectrometric data. Atmos. Chem. Phys. 9, 2891-2918 (2009). 
52. Fröhlich, R. et al. ACTRIS ACSM intercomparison-Part 2: intercomparison of ME-2 organic source apportionment results from 15 individual, co-located aerosol mass spectrometers. Atmos. Meas. Tech. 8, 2555-2576 (2015).

53. Crippa, M. et al. Organic aerosol components derived from 25 AMS data sets across Europe using a consistent ME-2 based source apportionment approach. Atmos. Chem. Phys. 14, 6159-6176 (2014).

54. Xu, W. et al. Effects of aqueous-phase and photochemical processing on secondary organic aerosol formation and evolution in Beijing, China. Environ. Sci. Technol. 51, 762-770 (2017).

55. Healy, R. M. et al. Predicting hygroscopic growth using single particle chemical composition estimates. J. Geophys. Res. Atmos. 119, 9567-9577 (2014).

56. Liu, D. et al. Size distribution, mixing state and source apportionment of black carbon aerosol in London during wintertime. Atmos. Chem. Phys. 14, 10061-10084 (2014).

57. Nakao, S. et al. Density and elemental ratios of secondary organic aerosol: application of a density prediction method. Atmos. Environ. 68, 273-277 (2013).

58. Peña, O. \& Pal, U. Scattering of electromagnetic radiation by a multilayered sphere. Comput. Phys. Comm. 180, 2348-2354 (2009).
Open Access This article is licensed under a Creative Commons Attribution 4.0 International License, which permits use, sharing, adaptation, distribution and reproduction in any medium or format, as long as you give appropriate credit to the original author(s) and the source, provide a link to the Creative Commons license, and indicate if changes were made. The images or other third party material in this article are included in the article's Creative Commons license, unless indicated otherwise in a credit line to the material. If material is not included in the article's Creative Commons license and your intended use is not permitted by statutory regulation or exceeds the permitted use, you will need to obtain permission directly from the copyright holder. To view a copy of this license, visit http://creativecommons. org/licenses/by/4.0/.

(c) The Author(s) 2018 